JP3I (Jurnal Pengukuran Psikologi dan Pendidikan Indonesia), 10(I), 202I, 60-66

D01: http://dx.doi.org/10.15408/ip3i.v10il.17150

http://journal.uinjkt.ac.id/index.php/jp3i

\title{
Construct Validity of Unidimensional General Self-Efficacy Using Confirmatory Factor Analysis
}

\author{
Santi Yudhistira, Deasyanti, Fellianti Muzdalifah \\ Faculty of Psychology, Universitas Negeri Jakarta, Indonesia \\ santiyudhistira@unj.ac.id
}

\begin{abstract}
Self-efficacy is a specific domain which is divided into several aspects (e.g., magnitude, strength, and generality) based on Bandura's theory. However, many researchers attempt to generalize the concept of self-efficacy to examine personal competence in a broader view. This study aims to test the validity of items on the General Self-Efficacy Scale (GSES), a measuring instrument that was developed by Ralf Schwarzer and designed by Matthias Jerusalem in 1979 to regulate the construction of self-efficacy as a broader concept of personality. This research used the Confirmatory Factor Analysis (CFA) method on 643 students in the Jabodetabek area to test the instrument's validity and the CFA test results showed that out of the 10 items tested, the written statement is valid to measure the General Self-Efficacy variable.
\end{abstract}

Keywords: general self-efficacy scale, construct validity, confirmatory factor analysis. 


\section{Introduction}

Self-efficacy is a belief in one's abilities (Bandura, 1997, Gaskill \& Hoy, 2002). Self-efficacy is defined as a person's assessment of their ability to organize and carry out the actions needed to achieve predetermined targets (Breso, Schaufeli, \& Salanova, 2011). Self-efficacy is a form of self-assessment of a person's ability to complete a task successfully (Zhang, 2014). Self-efficacy also refers to the perceived ability to learn or take action at a specified level (Bandura, 1997).

Individuals with high self-efficacy are more likely to set goals, develop strong cognitive mechanisms for knowledge acquisition, seek academic challenges, and survive adversity (Stubbs \& Maynard, 2017). People with high self-efficacy will choose to do challenging tasks and are optimistic about their ability to achieve goals. In contrast, those with low self-efficacy tend to think pessimistically about their ability to develop (Schwarzer, BaBler, Kwiatek, Schroder, \& Zhang, 1997; Demiroren, Turan, \& Oztuna, 2016). High self-efficacy may result in higher effort output, endurance, and consistency if compared to low self-efficacy (Gaskill et al., 2002; Schwarzer et al., 1997; Linnenbrink, \& Pintrich, 2002). Even when individuals have the same academic ability, someone with high self-efficacy still tends to have better tasks performance (Gaskill et al., 2002).

Various domains have explored the concept of self-efficacy, as such in education, business, athletics, career, health, and fitness (Schunk \& DiBenedetto, 2015). Researchers found that self-efficacy is influential in many aspects such as individuals' learning, motivation, self-regulation, self-esteem, locus of control, neuroticism, Well-Being, Health Behaviors, Coping, school achievement, depression, anxiety, orientation. towards the future, personality, stress assessment and so on (Bandura, 1997; Pajares, 1996; Schunk and Pajares, 2009; Chen, et.al, 2001; Luszczynska, Don a, \& Schwarzer, 2005).

Current researches defined self-efficacy as a specific domain which is divided into several aspects based on Bandura's theory. However, many researchers attempt to generalize the concept of selfefficacy to examine personal competence in broader view as reference to a person's self-confidence when facing demands in various new situations (Schwarzer et al., 1997; Juárez and Contreras, 2008). General self-efficacy is defined as a person's belief in their overall competence to influence the required performance in various achievement situations (Chen, Gully \& Eden, 2001) or an individual's perception of a person's ability to perform in various situations (Judge, et.al, in Chen, Gully \& Eden, 2001).

General self-efficacy acts as determiner in one's competence in facing various stressful demands or challenges in life (Schwarzer \& Jerusalem, 1995), and it is also considered as a relatively stable general belief to help individuals in facing adversities (Scherbaum, Charash, \& Kern, 2006). The concept of general self-efficacy reflects generalizations across multiple domains where people judge their own effectiveness. General self-efficacy exists as a universal construct characterized by basic beliefs inherent in all individuals. General self-efficacy aims to examine personal competence in dealing with various stressful situations effectively using a much broader perspective (Schwarzer et al., 1997; Zimmerman, 1995).

\section{General Self-Efficacy Scale}

Matthias Jerusalem and Ralf Schwarzer designed the General self-efficacy Scale (GSES) in 1979 to evaluate the construction of self-efficacy as a broader concept of personality (Schwarzer, et.al, 1997; Juárez and Contreras, 2008; Scholz, Doña, Sud, \& Schwarzer, 2002). The General self-efficacy scale's original version in German contained 20 statements and by 1981 it became 10 items scale. 
Table 1. Example of General Self-Efficacy Scale Items

\begin{tabular}{ll}
\hline 1 & If I am in trouble, I can usually think of a solution \\
2 & I can solve most problems if I invest the necessary effort. \\
3 & I can always manage to solve difficult problems if I try hard enough \\
\hline
\end{tabular}

The first GSES study was conducted on 430 participants from Germany, 959 participants from Spain, and 293 participants from China with internal consistency scores of 0.84, 0.81, and 0.91, respectively. GSES is a unidimensional instrument designed to see personal competence more broadly in handling various stressful situations effectively. Several countries have adapted and translated the GSES into several languages. Previous studies have discussed the internal consistency coefficients (Cronbach's Alpha) on the General Self-Efficacy Scale.

Table 2. Internal Consistency Coefficients General Self-Efficacy Scale in Various Countries

\begin{tabular}{ccc}
\hline Countries & Coefficient & N \\
\hline German & 0,81 & 7100 \\
Spanish & 0,81 & 959 \\
Hong kong & 0,85 & 1067 \\
China 2 & 0,85 & 1068 \\
Indonesia & 0,80 & 536 \\
Japan & 0,91 & 430 \\
South Korea & 0,88 & 147 \\
Columbia & 0,83 & 690 \\
Belgium & 0,84 & 175 \\
Canada & 0,88 & 367 \\
Denmark & 0,87 & 153 \\
Finland & 0,85 & 159 \\
Francis & 0,82 & 103 \\
Great Britain & 0,88 & 447 \\
Hungary & 0,88 & 158 \\
India & 0,75 & 398 \\
Iran & 0,84 & 802 \\
Italy & 0,79 & 144 \\
Netherlands & 0,85 & 911 \\
Peru & 0,80 & 994 \\
Poland & 0,85 & 690 \\
Portugal & 0,76 & 544 \\
Russia & 0,85 & 495 \\
Syria & 0,79 & 264 \\
United States of America & 0,87 & 1594 \\
\hline
\end{tabular}

The data in Table 2 shows that the GSES has been adapted by various countries with Cronbach's Alpha internal consistency coefficients ranging from 0.75 to 0.91 . These data indicate that the GSES has good internal consistency coefficients Cronbach's Alpha and has good reliability in measuring general selfefficacy (Schwarzer, et.al, 1997; Schwarzer, Born, Iwawaki, \& Lee, 1997, Scholz, Doña, Sud, \& Schwarzer, 2002). 


\section{Methods}

Participants in this study were undergraduate students from various universities in the Greater Jakarta area. There were 643 participants $(\mathrm{N}=643)$ consisting of 181 male participants $(28.15 \%)$ and 462 female participants (71.20\%). This research used confirmatory factor analysis (CFA) to measure the GSES's validity, considering that CFA is a reliable statistical procedure used to test hypotheses in model testing (Hoyle, 2004). CFA is a type of Structural Equation Modeling (SEM) that specifically examines measurement models related to observed measures or indicators and latent variables or factors (Brown, 2006; Prudon, 2015). CFA is often used during the scale development process to see the latent structure of test instruments such as questionnaires (Brown, 2006).

It is necessary to consider the fulfilment of the fit model criteria first before proceeding with the discussion about the statements' significance from the tested measuring instrument. To determine the model fit (fit index) on the measuring instrument, the researchers used the cut-off fit index criteria by looking at the values of the Chi-Square, Absolute Fit Indexes, namely Root mean square error approximation (RMSEA) and Standardized Root Mean Squared Residual ( SRMR) or Weighted Root Mean Square Residual (WRMR), and the value of Incremental Fit Indexes, namely the Comparative Fit Index (CFI) and the Tucker-Lewis Index (TLI) (Hu, \& Bentler, 1999; 1998; Brown, 2006; Chau \& Hocevar , 1995). Cut-off fit index showed RMSEA $<0.08$, SRMR $<0.08$ or WRMR $\leq 1.0$, CFI $>0.95$, and TLI $>0.9$ and Chi-Square (P-Value) $>0.05$ (Hu, \& Bentler, 1999; Byrne, 2012; Brown, 2006). After the model is declared fit, the next step should be to test whether the statement is significant or not to measure the desired variable using MPlus Version 7.11 software from Muthen and Muthen (2013).

\section{Results and Discussion}

Validity of the GSES measuring instrument construct was tested using first-order model and the initial test results showed that the model is not fit with Chi-Square of 662.774, df of 35, P-value of 0.000 , and RMSEA of 0.167 . Modification is required to obtain a fit model by releasing mutually correlated items. After going through the modification process, obtained a fit model with Chi-Square of 34.009, df of 23, Pvalue of 0.1749 , and RMSEA of 0.021 . As shown in the modification results, all values have met the fit model criteria in the CFA test.

Upon finding a fit model, the next required action is to test the significance of the GSES items by examining T-Value and P-Value. The items are significant only when having T-Value $>1.96$ and P-Value $<0.05$.

Table 3. Factor Loading General Self-Efficacy Scale

\begin{tabular}{cccccc}
\hline Items & Coefficient & $\boldsymbol{S . E}$ & T-Value & $\boldsymbol{P}$-Value & Sig \\
\hline Item 1 & 0.471 & 0.029 & 16.441 & 0.000 & Sig \\
Item 2 & 0.743 & 0,020 & 37.661 & 0.000 & Sig \\
Item 3 & 0.726 & 0,023 & 32.265 & 0.000 & Sig \\
Item 4 & 0.673 & 0,022 & 30.556 & 0.000 & Sig \\
Item 5 & 0.700 & 0,021 & 33.495 & 0.000 & Sig \\
Item 6 & 0.667 & 0,022 & 30.190 & 0.000 & Sig \\
Item 7 & 0.629 & 0,021 & 29.275 & 0.000 & Sig \\
Item 8 & 0.863 & 0,012 & 69.909 & 0.000 & Sig \\
Item 9 & 0.791 & 0,017 & 46.608 & 0.000 & Sig \\
Item 10 & 0.823 & 0,017 & 47.048 & 0.000 & Sig \\
\hline
\end{tabular}




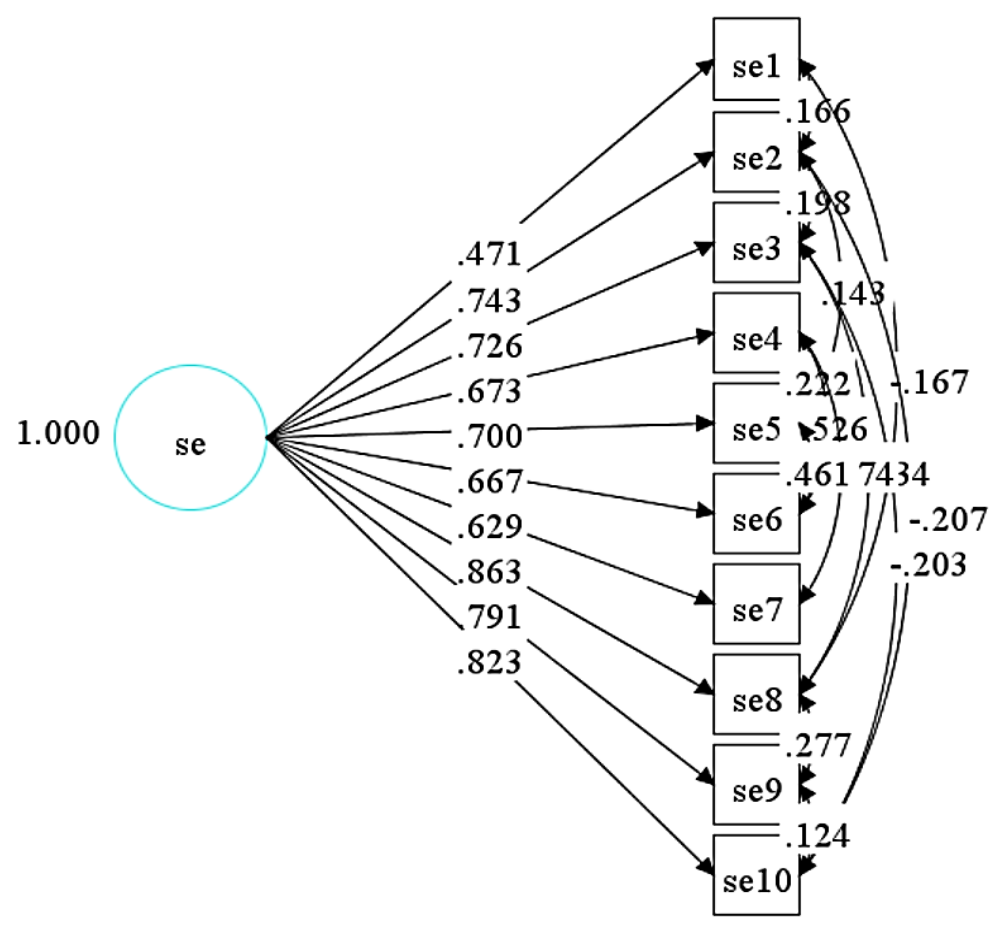

Figure 1. Model CFA after Modification

The data in Table 3 show that all items in GSES were statistically significant, having T-Value $>1.96$ and P-Value $<0.05$. All items in GSES are tested to be valid and no items were dropped as such all items confirmed may be used to measure general self-efficacy variables.

\section{Discussion}

When comparing the results of the CFA test in this study with previous research from Schwarzer et al., (1997) in Germany, Spain, and China, the comparison of the coefficient values of the 10 items tested is as follows:

Table 4. Comparison of Factor Loading General Self-Efficacy Scale with Germany, Spain, and China

\begin{tabular}{ccccc}
\hline Items & Indonesia & Germany & Spain & China \\
\hline Item 1 & 0.471 & 0,42 & 0,29 & 0,70 \\
Item 2 & 0.743 & 0,48 & 0,39 & 0,49 \\
Item 3 & 0.726 & 0,55 & 0,38 & 0,56 \\
Item 4 & 0.673 & 0,63 & 0,63 & 0,81 \\
Item 5 & 0.700 & 0,67 & 0,68 & 0,78 \\
Item 6 & 0.667 & 0,75 & 0,72 & 0,76 \\
Item 7 & 0.629 & 0,60 & 0,73 & 0,81 \\
Item 8 & 0.863 & 0,54 & 0,56 & 0,62 \\
Item 9 & 0.791 & 0,62 & 0,61 & 0,74 \\
Item 10 & 0.823 & 0,52 & 0,58 & 0,75 \\
\hline
\end{tabular}

The data in Table 4 shows that the coefficient values in this study mostly have higher values when compared to Germany and Spain (as items 2, 3, 8 and 10). Meanwhile, China has higher average coefficient value than the coefficient value in this study. However, the results in these four countries show that all statements from the General Self-Efficacy Scale are valid to measure the construct of general self-efficacy. 


\section{Conclusion}

This paper attempted to validate the unidimensional general self-efficacy scale using confirmatory factor analysis (CFA). Prior studies showed that a unidimensional general self-efficacy scale has good psychometric properties. The statement is supported by the confirmatory factor analysis results of this study that showed the unidimensional general self-efficacy scale is a valid measuring tool and can measure general self-efficacy which is designed to see personal competence and effectiveness when dealing with various stressful situations in broader terms.

\section{References}

Bandura, A. (1997). Self-efficacy: the exercise of control. New York: W. H. Freeman and Company.

Breso, E., Schaufeli, W. B., \& Salanova, M. (2011). Can a self-efficacy-based intervention decrease burnout, increase engagement, and enhance performance? A quasi-experimental study. High Education, 61, 339-355.

Brown, T. A. (2006). Confirmatory factor analysis for applied research. New York: The Guilford Press.

Byrne, B. M. (2012). Structural equation modeling with Mplus basic concept, applications, and programming. New York : Taylor \& Francis Group.

Chau, H., \& Hocevar, D. (1995). The effect of number of measured variables on goodfness-of fit in confirmatory factor analysis. Report - Evaluatif/Feasibility, 142.

Chen, G., Gully, S., \& Eden, D. (2001). Validation of a new general self-efficacy scale. Organizational Research Methods, 4(1), 62-83.

Demiroren, M., Turan, S., \& Oztuna, D. (2016). Medical student's self-efficacy in problem-based learning and its relationship with self-regulated learning. Medical Education Online, 21.

Gaskill, P. J., \& Hoy, A. W. (2002). Self-efficacy and self-regulated learning: the dynamic duo in school performance. Improving academic achievement, 9, 185-207.

Hoyle, R.H. (2004). Confirmatory factor analysis. In M. Lewis-Back, A. Bryman, \& T. Liao (Eds.). Encyclopedia of social science research methods, 1, 169-175.

$\mathrm{Hu}, \mathrm{L} \&$ Bentler, P. M. (1999). Cutoff criteria for fit indexes in covariance structure analysis: Conventional criteria versus new alternatives. Structural Equation Modeling: A Multidisciplinary Journal, 6 (1), 1-55.

Hu, L., \& Bentler, P. M. (1998). Fit indices in covariance structure modeling: sensitivity to under parameterized model misspecification. Psychological Methods, 3(4), 424-453.

Juárez, F., \& Contreras, F. (2008). Psychometric properties of the general self-efficacy scale in a Colombian sample. International Journal of Psychological Research, 1(2), 6-12.

Linnenbrink, E. A., \& Pintrich, P. R. (2002). Motivation as an enabler for academic success. Psychology Review, 31.

Luszczynska, A., Doña, B.G., \& Schwarzer, R. (2005). General self-efficacy in various domains of human functioning: Evidence from five countries. International Journal of Psychology, 40 (2), 80-89.

Luszczynska, A., Scholz, U., \& Schwarzer, R. (2005). The general self-efficacy scale: multicultural validation studies. The Journal og Psychology, 139(5), 439-457.

Muthén, L.K. and Muthén, B.O. (1998-2012). Mplus user's guide. Seventh edition. Los Angeles, CA: Muthén \& Muthén.

Pajares, F. (1996). Self-efficacy beliefs in achievement settings. Review of Educational Research, 66, 543-578.

Prudon, P. (2015). Confirmatory factor analysis as a tool in research using questionnaires a critique. Comprehensive Psychology, 4(10), 1-18. 
Scherbaum, C.A., Charash, Y.C., \& Kern, M.J. (2006). Measuring general self-efficacy: a comparison pf three measures using item response theory. Educational and psychological measurement, 66(6), 10471063.

Scholz, U., Doña, B.G., Sud, S. \& Schwarzer, R. (2002). Is general self-efficacy a universal construct? psychometric findings from 25 countries. European Journal of Psychological Assessment, 18(3), 242-251.

Schunk, D. H., \& DiBenedetto, M. K. (2015). Self-efficacy: education aspects. International Encyclopedia of the Social \& Behavioral Sciences, $\left(2^{\text {nd }}\right)$ 21, 515-521.

Schunk, D. H., \& Pajares, F. (2009). Self-efficacy theory. In K. R. Wentzel \& A. Wigfield (Eds.), Handbook of motivation at school. New York : Routledge.

Schwarzer, R., Babler, J., Kwiatek, P., Schroder, K., \& Zhang, J.X. (1997). The assessment of optimistic self-beliefs: comparison of the german, spanish, and chinese versions of the general self-efficacy scale. Applied Psychology: An International Review, 46(1), 69-88.

Schwarzer, R., Born, A., Iwawaki, S., Lee, Y.-M. (1997). The assessment of optimistic self-beliefs: Comparison of the Chinese, Indonesian, Japanese, and Korean versions of the General Self-Efficacy scale. Psychologia: An International Journal of Psychology in the Orient, 40(1), 1-13.

Schwarzer, R., \& Jerusalem, M. (1995). Generalized self-efficacy scale. In J. Weinman, S. Wright, \& M. Johnston (Eds.), Measures in health psychology: A user's portfolio. Causal and control beliefs, 35-37.

Stubbs, N. S., \& Maynard, D. M. B. (2017). Academic self-efficacy, school engagement and family functioning, among postsecondary students in the Caribbean. Journal Child Family Studies. 26, 792799.

Zhang, B., Yan, X., Zhao, F., \& Yuan, F. (2015). The relationship between perceived stress and adolescent depression: the roles of social support and gender. Social Indic Res, 123, 501-518.

Zimmerman, B. J. (1995). Self-efficacy in changing societies. New York : Cambridge University Press. 